\title{
Wood Creosote Inhibits Calcium Mobilization in Guinea Pig Colonic Smooth Muscle
}

\author{
Hirofumi Morino,* Koji Ataka, Masafumi Ito, and Tomoo Kuge \\ Taiko Pharmaceutical Co., Ltd.; 3-34-14 Uchihonmachi, Suita, Osaka 564-0032, Japan. \\ Received January 26, 2004; accepted April 7, 2004
}

\begin{abstract}
Wood creosote, a mixture of simple phenolic compounds, has long been used as an herbal antidiarrheal medicine. Previous studies have shown that wood creosote has antimotility activity on the gastrointestinal (GI) tract, although its mechanism of action is not completely understood. The in vitro efficacy of wood creosote on calcium mobilization in guinea pig colonic smooth muscle was evaluated using a digital video camera system mounted on an inverted fluorescence microscope. The effects of wood creosote on spontaneous periodic increases in the free cytosolic calcium concentration $\left(\left[\mathrm{Ca}^{2+}\right]_{\mathrm{i}}\right)$, acetylcholine $(\mathrm{ACh})$-enhanced periodic increases in $\left[\mathrm{Ca}^{2+}\right]_{i}$, and tetrodotoxin- or nifedipine-resistant spontaneous periodic increases in $\left[\mathrm{Ca}^{2+}\right]_{i}$ were evaluated. Wood creosote decreased the amplitude of spontaneous $\left(\mathrm{IC}_{50}=21 \mu \mathrm{g} / \mathrm{ml}\right)$ and $\mathrm{ACh}$-enhanced $\left(\mathrm{IC}_{50}=40 \mu \mathrm{g} / \mathrm{ml}\right)$ periodic increases in $\left[\mathrm{Ca}^{2+}\right]_{i}$ in guinea pig colonic smooth muscle. Wood creosote also decreased the amplitude of both tetrodotoxinand nifedipine-resistant spontaneous periodic increases in $\left[\mathrm{Ca}^{2+}\right]_{i^{*}}$. These results suggest that antimotility activity through inhibition of $\mathrm{Ca}^{2+}$ mobilization in the GI tract is at least partially responsible for the antidiarrheal activity of wood creosote. Wood creosote may exert its antimotility effect, at least in part, on network regions of interstitial cells of Cajal, which act as pacemaker cells and mediators of neurotransmission in the GI tract.
\end{abstract}

Key words phenolic compounds; antimotility; calcium mobilization; antidiarrheal agent; colon

Spontaneous phasic contraction of the gastrointestinal (GI) tract is basic to peristaltic movements. The spontaneous phasic contraction is driven by spontaneous cyclic depolarizations, the so-called slow waves. These slow waves are believed to be generated by interstitial cells of Cajal (ICC) acting as pacemaker cells within the GI tract. ${ }^{1-3)}$ The ICC can be found in the myenteric plexus region and form enteric neural network regions. These cells are electrically coupled to the smooth muscles via gap junctions. $W / W^{v}$ mice, which have few enteric neural network regions of ICC due to mutations, lack the ability to generate electrical rhythmicity in the GI tract, which results in a severe anomaly of GI motility. This indicates that ICC plays a central role in GI motility. ${ }^{4-6)}$ The slow waves activate L-type $\mathrm{Ca}^{2+}$ channels on smooth muscle cells, and as a result external $\mathrm{Ca}^{2+}$ enters the cytoplasm. Furthermore, biochemical studies have clearly demonstrated that the increase in free cytosolic calcium concentration $\left(\left[\mathrm{Ca}^{2+}\right]_{\mathrm{i}}\right)$ triggers activation of the contractile elements in smooth muscle. ${ }^{7,8)}$ Therefore the measurement of $\mathrm{Ca}^{2+}$ mobilization is a very important method for understanding the mechanisms of action of medications targeting the GI tract.

Wood creosote (CAS no. 8021-39-4), which is the principal active ingredient in Seirogan ${ }^{\mathrm{TM}}$, has been used as a traditional herbal antidiarrheal medicine for more than a century in Asia. Wood creosote is produced by the distillation of wood tar and is composed of simple phenolic compounds such as phenol, guaiacol, and creosol $^{9)}$; wood creosote is chemically distinct and completely different from coal tar creosote (CAS no. 8001-58-9), which is produced from coal tar.

No serious adverse events have been reported with wood creosote. Furthermore, wood creosote was safe and well tolerated in healthy subjects in clinical studies ${ }^{10,11)}$ and has also been found to lack oncogenic potential. ${ }^{12)}$ Wood creosote has inhibitory effects on both intestinal motility ${ }^{13-16)}$ and secretion $^{16-18)}$ in vitro and has been shown to have antidiarrheal activity in animal models of diarrhea. ${ }^{13,16)}$ Previous studies demonstrated that wood creosote suppresses intestinal peristaltic movements and contractions of rat and guinea pig ileal longitudinal muscles. ${ }^{14-16)}$ However, to the best of our knowledge, the effect of wood creosote on $\mathrm{Ca}^{2+}$ mobilization in the GI tract has not been evaluated.

The objective of the present set of experiments was to evaluate the in vitro efficacy of wood creosote on $\mathrm{Ca}^{2+}$ mobilization within the GI tract by measuring $\mathrm{Ca}^{2+}$ concentrations using the standard Fura-2 method.

\section{MATERIALS AND METHODS}

Tissue Preparations Animals were handled according to "Guiding Principles for the Care and Use of Animals in the Field of Physiological Sciences" of the Physiological Society of Japan. Male Hartley guinea pigs (5-6 weeks) were purchased from Japan SLC, Inc. (Shizuoka, Japan) and the animals were housed two per cage with the usual 12-h light and 12-h dark cycle, and controlled temperature $\left(21^{\circ} \mathrm{C}\right)$ and humidity $(65 \%)$. Standard chow and tap water were provided ad libitum. All animals were anesthetized with inhalation of diethyl ether and euthanized by decapitation. A section of the distal colon was isolated and placed in a physiological salt solution (PSS). The lumen of the distal colon was cleaned gently with PSS. A segment $(1-1.5 \mathrm{~cm})$ of the distal colon was dissected, and a polystyrene pipette $6 \mathrm{~mm}$ in diameter was inserted into the lumen. The longitudinal and circular muscle layers were separated from the underlying mucosal layer. The tissue containing longitudinal and circular muscle layers was pinned open in a chamber (Glass Bottom Microwell Dishes, part no. P35GC0-0-10-C, MatTek Corporation, Ashland, MA, U.S.A.; volume approximately $2 \mathrm{ml}$ ) with a silicon rubber seat at the bottom. The silicon rubber seat was made from Sylgard (silicon elastomer, Dow Corning Corporation, Midland, MI, U.S.A.). The muscle tissue preparation was continuously perfused with oxygenated Krebs Ringer bicarbonate (KRB) solution for $1 \mathrm{~h}$ at $32^{\circ} \mathrm{C}$ before dye loading. 
The KRB solution ( $\mathrm{pH} 7.35$ at $32^{\circ} \mathrm{C}$ ) contained (mM): 120.4 $\mathrm{NaCl}, 5.9 \mathrm{KCl}, 2.5 \mathrm{CaCl}_{2}, 1.2 \mathrm{MgCl}_{2}, 5.6$ glucose, 15.5 $\mathrm{NaHCO}_{3}$, and $1.2 \mathrm{NaH}_{2} \mathrm{PO}_{4}$.

Loading Muscles with Fluorescent Indicator and Fluorescence Imaging The muscle tissue preparations were treated with $5 \mu \mathrm{M}$ of the $\mathrm{Ca}^{2+}$-sensitive indicator Fura- 2 acetoxymethyl ester (Fura-2 AM) and $0.02 \%$ of the noncytotoxic detergent cremophor EL in KRB solution for $1 \mathrm{~h}$ at room temperature. The muscle tissue preparations were illuminated alternatively with $340-\mathrm{nm}$ and $380-\mathrm{nm}$ light, and the ratio of the intensity of the emission fluorescence $\left(F_{340} / F_{380}\right)$ in the region of interest was measured through a barrier filter of $510 \mathrm{~nm}$ using a digital video camera system (AQUACOSMOS, Hamamatsu Photonics, Hamamatsu, Japan) mounted on an inverted fluorescence microscope (TE2000-U, Nikon, Tokyo, Japan). $\left[\mathrm{Ca}^{2+}\right]_{\mathrm{i}}$ was calculated from the ratio of the intensity of emission fluorescence according to the following formula ${ }^{19)}$ :

$$
\left[\mathrm{Ca}^{2+}\right]_{\mathrm{i}}=K_{\mathrm{d}} \beta\left(R-R_{\min }\right) /\left(R_{\max }-R\right)
$$

The maximum fluorescence ratio $\left(R_{\max }\right)$ was obtained by exposing cells to $10 \mu \mathrm{M}$ of ionomycin, a $\mathrm{Ca}^{2+}$ ionophore, in KRB solution. Immediately after determining $R_{\max }$, the solution was replaced with $\mathrm{Ca}^{2+}$-free $\mathrm{KRB}$ solution containing ionomycin $10 \mu \mathrm{M}$ and $5 \mathrm{~mm}$ ethyleneglycol-bis[ $\beta$-aminoethyl ether $] N, N, N^{\prime}, N^{\prime}$-tetraacetic acid (EGTA), and the minimum fluorescence ratio $\left(R_{\min }\right)$ was determined. The ratio of $F_{380}$ in $\mathrm{Ca}^{2+}$-free KRB solution containing ionomycin $10 \mu \mathrm{M}$ and $5 \mathrm{~mm}$ EGTA to that in KRB solution containing ionomycin $10 \mu \mathrm{M}(\beta)$ was determined in the experiments described above. We employed a dissociation constant $\left(K_{\mathrm{d}}=224 \mathrm{~nm}\right)$ for the $\mathrm{Ca}^{2+}$-Fura-2 complex for calculation of $\left[\mathrm{Ca}^{2+}\right]_{\mathrm{i}} \cdot{ }^{19)}$

Application of Medications All medications were added to oxygenated KRB solution and applied to a recording chamber using a perfusion system. Loperamide, a common antidiarrheal medication, was added in a dimethylsulfoxide (DMSO) solution, and the final concentration of vehicle was less than $0.1 \%(\mathrm{v} / \mathrm{v})$; this concentration of DMSO had no effect on spontaneous periodic increases in $\left[\mathrm{Ca}^{2+}\right]_{\mathrm{i}}$. The inhibitory effects of medications on spontaneous periodic increases in $\left[\mathrm{Ca}^{2+}\right]_{\mathrm{i}}$ were calculated as the $50 \%$ inhibitory concentration $\left(\mathrm{IC}_{50}\right)$; application of high concentrations of medications, such as wood creosote, the six major constituents of wood creosote (guaiacol, creosol, $p$-cresol, phenol, $o$-cresol, and 4-ethylguaiacol), and loperamide, nearly abolished the spontaneous periodic increases in $\left[\mathrm{Ca}^{2+}\right]_{\mathrm{i}}$.

Medications and Chemicals Wood creosote (lot TA-03, Taiko Tec Co., Ltd., Osaka, Japan) used in this study contained 26\% (w/w) guaiacol, 19\% creosol, 9\% p-cresol, 9\% phenol, 7\% $o$-cresol, 6\% 4-ethylguaiacol, and 24\% other compounds, principally consisting of simple phenolic compounds. ${ }^{9)}$ Fura-2 AM was obtained from Dojindo (Kumamoto, Japan) and tetrodotoxin (TTX) was obtained from Wako Pure Chemical (Osaka, Japan); cytochalasin D, wortmannin, acetylcholine chloride (ACh), and loperamide hydrochloride were from Sigma-Aldrich (St. Louis, MO, U.S.A.); and guaiacol, creosol, $p$-cresol, phenol, $o$-cresol, and 4-ethylguaiacol were from Tokyo Kasei Kogyo (Tokyo, Japan). All other reagents were of the highest grade commercially available.
Statistical Analysis Results are presented as mean \pm standard error of the mean (S.E.M.) values and associated 95\% confidence intervals where applicable. Statistical significance was determined using Student's $t$-test. A $p$ value of less than 0.05 was considered to be statistically significant.

\section{RESULTS}

Experimental Setup We visualized Fura-2-loaded colonic smooth muscle fibers under an inverted fluorescence microscope with a CCD camera; the depth of field was focused on longitudinal muscle layers (Fig. 1). A spontaneous increase in fluorescence intensity frequently occurred in one muscle fiber and then spread quickly in a wave-like fashion to other muscle fibers. Changes in fluorescence intensities in a window $(350 \times 350 \mu \mathrm{m})$ were recorded and $\left[\mathrm{Ca}^{2+}\right]_{\mathrm{i}}$ was evaluated using the standard ratiometric method.

Spontaneous Periodic Increases in $\left[\mathrm{Ca}^{2+}\right]_{i}$ Under the study conditions, spontaneous periodic increases in $\left[\mathrm{Ca}^{2+}\right]_{\mathrm{i}}$ were observed (Fig. 2A). The pseudocolor 340/380 ratio images at minimal and maximal levels of $\left[\mathrm{Ca}^{2+}\right]_{i}$ are shown in Fig. 2B and $\mathrm{C}$. The frequency of spontaneous periodic increases in $\left[\mathrm{Ca}^{2+}\right]_{\mathrm{i}}$ was $19 \pm 5$ cycles/min $(n=6)$. When external $\mathrm{KRB}$ solution containing $2.5 \mathrm{mM} \mathrm{CaCl}_{2}$ was replaced with $\mathrm{Ca}^{2+}$-free $\mathrm{KRB}$ solution, the spontaneous periodic increases in $\left[\mathrm{Ca}^{2+}\right]_{\mathrm{i}}$ completely disappeared (Fig. 2D, 0 to 7.5 min) and subsequent replacement of the KRB solution containing $2.5 \mathrm{mM} \mathrm{CaCl}_{2}$ resulted in recovery of the spontaneous periodic increases in $\left[\mathrm{Ca}^{2+}\right]_{\mathrm{i}}$ (Fig. 2D, 7.5 to $14 \mathrm{~min}$ ), indicating that the increases in $\left[\mathrm{Ca}^{2+}\right]_{\mathrm{i}}$ is dependent upon influx from external $\mathrm{Ca}^{2+}$. To suppress the movement of smooth muscle, ${ }^{20)}$ we added $5 \mu \mathrm{M}$ of cytochalasin $\mathrm{D}$, a capping agent of actin filaments, ${ }^{21)}$ and $5 \mu \mathrm{M}$ of wortmannin, a myosin light chain kinase inhibitor ${ }^{22)}$ to the KRB solution. These drugs had no effect on spontaneous periodic increases in $\left[\mathrm{Ca}^{2+}\right]_{i}$ (Fig. 2E).

Effect of Wood Creosote on Spontaneous Periodic Increases in $\left[\mathbf{C a}^{2+}\right]_{i}$ We investigated the effects of wood creosote on the spontaneous periodic increases in $\left[\mathrm{Ca}^{2+}\right]_{i}$ in muscle tissue preparations. When wood creosote at various concentrations was added to a recording chamber, the amplitude of spontaneous periodic increases in $\left[\mathrm{Ca}^{2+}\right]_{\mathrm{i}}$ decreased in a dose-dependent manner (Figs. 3A, C). A dose-response curve for wood creosote is shown in Fig. 3D $\left(\mathrm{IC}_{50}=21.0\right.$

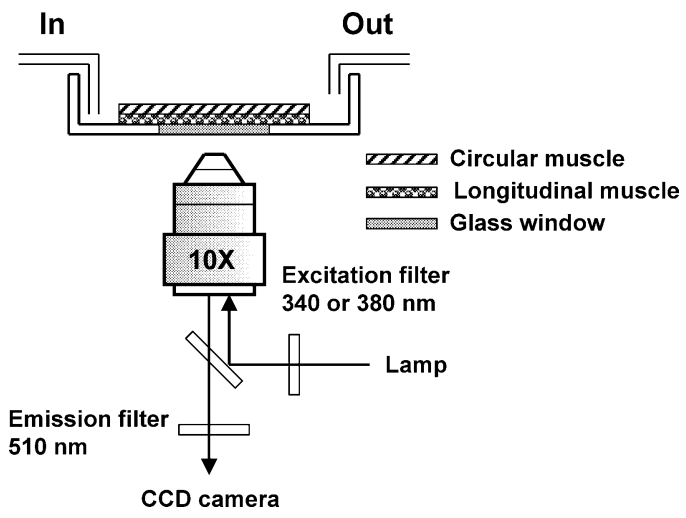

Fig. 1. Experimental Setup

Illustration of the tissue illumination and recording setup. Changes in fluorescence intensity were recorded from the longitudinal muscle layer viewed from the serosal side. 
A



B

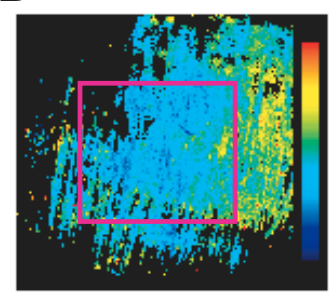

C

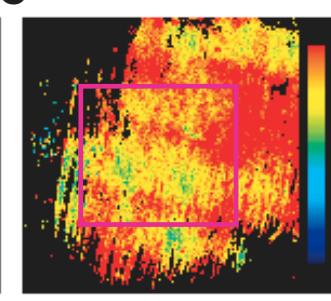

$1 \overline{165 \propto \mathrm{m}}$

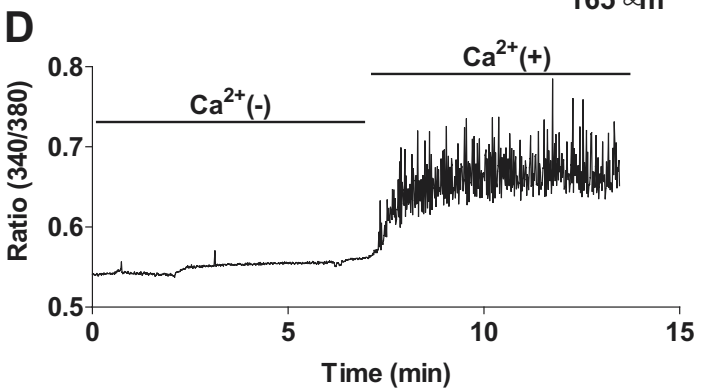

E

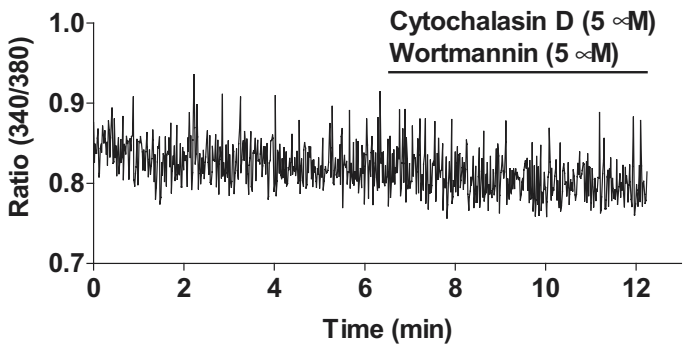

Fig. 2. Spontaneous Periodic Increases in $\left[\mathrm{Ca}^{2+}\right]_{\mathrm{i}}$ in Guinea Pig Colonic Smooth Muscle

(A) Spontaneous periodic increases in $\left[\mathrm{Ca}^{2+}\right]_{\mathrm{i}}$. Changes in fluorescence intensities in a window $(350 \times 350 \mu \mathrm{m})$ were recorded. (B) Pseudocolor 340/380 ratio image showing the minimal level of $\left[\mathrm{Ca}^{2+}\right]_{\mathrm{i}}$. Red rectangular shows the recording window. (C) Pseudocolor 340/380 ratio image showing the maximal level of $\left[\mathrm{Ca}^{2+}\right]_{i}$. (D) Effects of extracellular $\mathrm{Ca}^{2+}$ on spontaneous periodic increases in $\left[\mathrm{Ca}^{2+}\right]_{\mathrm{i}}$ in guinea pig colonic smooth muscle. External $\mathrm{KRB}$ solution containing $2.5 \mathrm{~mm} \mathrm{CaCl}_{2}$ was replaced with $\mathrm{Ca}^{2+}$-free $\mathrm{KRB}$ solution (D, 0 to $7.5 \mathrm{~min}$ ), and then $\mathrm{Ca}^{2+}$-free $\mathrm{KRB}$ solution was replaced with $\mathrm{KRB}$ solution containing $2.5 \mathrm{~mm} \mathrm{CaCl} 2$ (D, 7.5 to $14 \mathrm{~min}$ ). (E) Effects of cytochalasin $\mathrm{D}$ and wortmannin on spontaneous periodic increases in $\left[\mathrm{Ca}^{2+}\right]_{\mathrm{i}}$ in guinea pig colonic smooth muscle. $\mu \mathrm{g} / \mathrm{ml})$. The amplitude of spontaneous periodic increases in $\left[\mathrm{Ca}^{2+}\right]_{\mathrm{i}}$ recovered when the muscle tissue preparations were washed with KRB solution after $180 \mu \mathrm{g} / \mathrm{ml}$ of wood creosote was added to the recording chamber (Fig. 3B). This result indicates that the inhibition of spontaneous periodic increases in $\left[\mathrm{Ca}^{2+}\right]_{\mathrm{i}}$ induced by wood creosote is reversible.

Effect of Major Six Constituents of Wood Creosote and Loperamide on Spontaneous Periodic Increases in $\left[\mathrm{Ca}^{2+}\right]_{i}$ The six major constituents of wood creosote also inhibited spontaneous periodic increases in $\left[\mathrm{Ca}^{2+}\right]_{\mathrm{i}}$. Of the six major constituents, 4-ethylguaiacol was the most effective (Table 1). The inhibitory potency of loperamide was equivalent to that of 4-ethylguaiacol.

Effect of Wood Creosote on ACh-induced $\left[\mathrm{Ca}^{2+}\right]_{i}$ Changes In previous studies, wood creosote suppressed ACh-induced tonic contractions of guinea pig ileum. ${ }^{14-16)}$
A

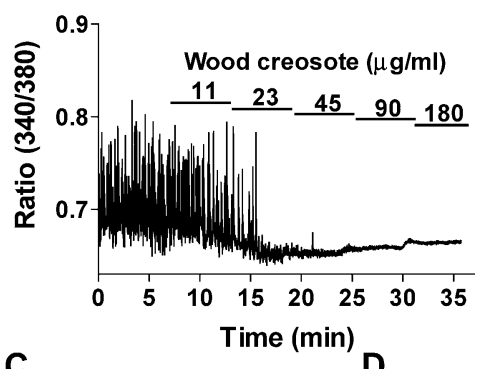

B

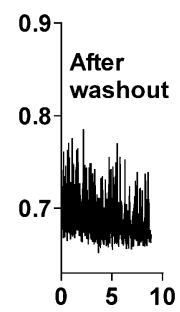



Fig. 3. Effects of Wood Creosote on Spontaneous Periodic Increases in $\left[\mathrm{Ca}^{2+}\right]_{\mathrm{i}}$ in Guinea Pig Colonic Smooth Muscle

(A) Wood creosote at various concentrations was added to the recording chamber. (B) Changes in $\left[\mathrm{Ca}^{2+}\right]_{i}$ in muscle tissue preparations $25 \mathrm{~min}$ after application of $180 \mu \mathrm{g} / \mathrm{ml}$ of wood creosote followed by a washout with KRB solution. (C) These traces with a fast time scale show parts of the recording trace in Fig. 3A. Left, changes in $\left[\mathrm{Ca}^{2+}\right]$. in the absence of wood creosote. Right, changes in $\left[\mathrm{Ca}^{2+}\right]$. after application of $23 \mu \mathrm{g} / \mathrm{ml}$ of wood creosote. (D) Dose-response curve. The mean amplitude of $\left[\mathrm{Ca}^{2+}\right]_{\mathrm{i}}$ was calculated from the amplitudes of periodic increases in $\left[\mathrm{Ca}^{2+}\right]_{\mathrm{i}}$ between 4 and $6 \mathrm{~min}$ after application of wood creosote at various concentrations. $100 \%$ of the vertical axis, amplitude (\%), is the mean amplitude of $\left[\mathrm{Ca}^{2+}\right]$; between 0 and 2 min after initiation of recording (nomedication). With no application of medication, spontaneous periodic increases in $\left[\mathrm{Ca}^{2+}\right]_{\mathrm{i}}$ were sustained for $35 \mathrm{~min}(>90 \%)$. The data in Fig. $3 \mathrm{D}$ are representative of six independent experiments.

Table 1. Inhibition of Spontaneous Periodic Increases in $\left[\mathrm{Ca}^{2+}\right]_{\mathrm{i}}$ in Guinea Pig Colonic Smooth Muscle by the Six Major Constituents of Wood Creosote

\begin{tabular}{|c|c|c|c|}
\hline Compound & $\mathrm{IC}_{50}(\mu \mathrm{M})$ & $95 \%$ confidence intervals $(\mu \mathrm{M})$ & Relative abundance in wood creosote ${ }^{a)}(\%)$ \\
\hline Wood creosote & $21.0(\mu \mathrm{g} / \mathrm{ml})$ & $10.5-40.0(\mu \mathrm{g} / \mathrm{ml})$ & \\
\hline Phenol & 16.6 & $4.6-60.8$ & 14.5 \\
\hline 2-Methylphenol (o-cresol) & 14.3 & $2.9-70.9$ & 3.2 \\
\hline 4-Methylphenol ( $p$-cresol) & 36.9 & $22.8-59.6$ & 13.6 \\
\hline 2-Methoxyphenol (guaiacol) & 13.2 & $6.3-27.3$ & 23.8 \\
\hline 4-Methylguaiacol (creosol) & 12.7 & $9.5-17.1$ & 19.0 \\
\hline 4-Ethylguaiacol & 6.5 & $3.0-14.0$ & 6.4 \\
\hline Loperamide & 9.6 & $4.5-20.5$ & \\
\hline
\end{tabular}



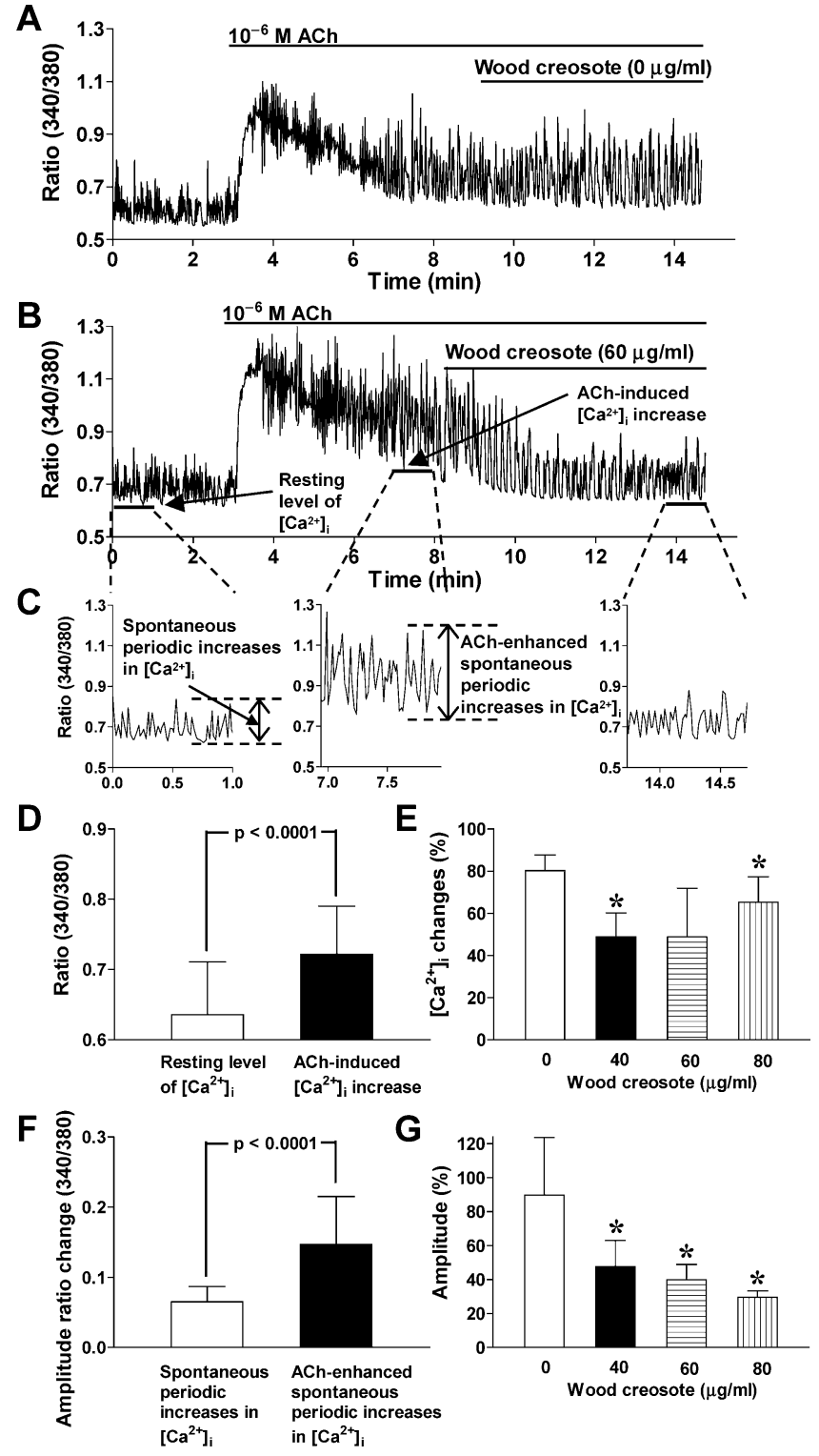

Fig. 4. Effects of Wood Creosote on ACh-Induced $\left[\mathrm{Ca}^{2+}\right]_{\mathrm{i}}$ Changes in Guinea Pig Colonic Smooth Muscle

(A) Changes in $\left[\mathrm{Ca}^{2+}\right]_{\text {i }}$ produced by $\mathrm{ACh}\left(10^{-6} \mathrm{M}\right)$ when $\mathrm{KRB}$ solution without wood creosote was added to the recording chamber after application of ACh. (B) Effects of wood creosote $60 \mu \mathrm{g} / \mathrm{ml}$ on ACh-induced $\left[\mathrm{Ca}^{2+}\right]_{\mathrm{i}}$ changes when added to the recording chamber after application of ACh. (C) These traces with a fast time scale show parts of the recording trace in Fig. 4B. (D) ACh-induced $\left[\mathrm{Ca}^{2+}\right]$ increase. (E) Effects of wood creosote on the $\mathrm{ACh}$-induced $\left[\mathrm{Ca}^{2+}\right]_{\mathrm{i}}$ increase. Wood creosote at various concentrations was added to the recording chamber 6 min after application of ACh. Each bar was calculated from the mean value of $\left[\mathrm{Ca}^{2+}\right]_{\text {, between }} 10$ and $12 \mathrm{~min}$ after application of ACh. $100 \%$ of the vertical axis, $\left[\mathrm{Ca}^{2+}\right]_{\text {i }}$ changes $(\%)$, is the mean value of $\left[\mathrm{Ca}^{2+}\right]_{\mathrm{i}}$ be tween 4 and $6 \mathrm{~min}$ after application of ACh. (F) ACh-enhanced spontaneous periodic increases in $\left[\mathrm{Ca}^{2+}\right]_{\mathrm{i}}$. (G) Effects of wood creosote on ACh-enhanced spontaneous periodic increases in $\left[\mathrm{Ca}^{2+}\right]$. Data were calculated as described in Fig. 4E except for $100 \%$ of the vertical axis, amplitude (\%), is the mean amplitude of $\left[\mathrm{Ca}^{2+}\right]_{i}$ between 4 and 6 min after application of ACh. The data in Fig. 4D and F are representative of 26 independent experiments. The data in Figs. 4E and G are representative of five to eight independent experiments. $*$ Significantly different from application of $0 \mu \mathrm{g} / \mathrm{ml}$ wood creosote $(p<0.05)$

Therefore, under our experimental conditions for $\left[\mathrm{Ca}^{2+}\right]_{\mathrm{i}}$ measurement, we investigated whether ACh induced changes in $\left[\mathrm{Ca}^{2+}\right]_{\mathrm{i}}$ in the muscle tissue preparation. ACh increased the resting level of $\left[\mathrm{Ca}^{2+}\right]_{\mathrm{i}}\left(\mathrm{ACh}\right.$-induced $\left[\mathrm{Ca}^{2+}\right]_{\mathrm{i}}$ increase) and enhanced the spontaneous periodic increases in $\left[\mathrm{Ca}^{2+}\right]_{\mathrm{i}}$ (ACh-enhanced spontaneous periodic increases in $\left[\mathrm{Ca}^{2+}\right]_{\mathrm{i}}$ ) (Figs. 4A, D, F). We then examined the effect of wood cre-



Fig. 5. Effects of TTX on Spontaneous Periodic Increases in $\left[\mathrm{Ca}^{2+}\right]_{i}$ in Guinea Pig Colonic Smooth Muscle

TTX $250 \mathrm{~nm}$ was added to the recording chamber, and then wood creosote $40 \mu \mathrm{g} / \mathrm{ml}$ was added. The TTX had little effect on spontaneous periodic increases in $\left[\mathrm{Ca}^{2+}\right]_{\mathrm{i}}$. In the presence of TTX, wood creosote inhibited the spontaneous periodic increases in $\left[\mathrm{Ca}^{2+}\right]_{\mathrm{i}}$.

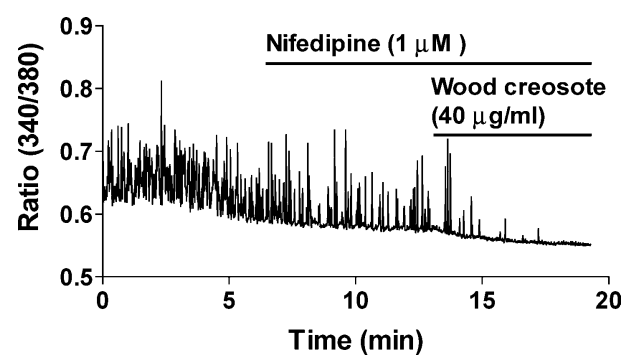

Fig. 6. Effect of Wood Creosote on Dihydropyridine-Resistant Spontaneous Periodic Increases in $\left[\mathrm{Ca}^{2+}\right]_{\mathrm{i}}$ in Guinea Pig Colonic Smooth Muscle

In the presence of nifedipine $1 \mu \mathrm{M}$, dihydropyridine-resistant periodic increases in $\left[\mathrm{Ca}^{2+}\right]_{\mathrm{i}}$ were observed. Wood creosote $40 \mu \mathrm{g} / \mathrm{ml}$ inhibited the dihydropyridine-resistant periodic increases in $\left[\mathrm{Ca}^{2+}\right]_{\mathrm{i}}$.

osote on ACh-induced $\left[\mathrm{Ca}^{2+}\right]_{\mathrm{i}}$ changes. Wood creosote inhibited both the ACh-induced $\left[\mathrm{Ca}^{2+}\right]_{\mathrm{i}}$ increase and the ACh-enhanced spontaneous periodic increases in $\left[\mathrm{Ca}^{2+}\right]_{\mathrm{i}}$ (Fig. 4B, 9 to 15 min, right side of $\mathrm{C}, \mathrm{E}, \mathrm{G})$.

Mechanisms Underlying $\mathrm{Ca}^{2+}$ Mobilization-Inhibitory Activity of Wood Creosote To investigate the mechanism underlying the $\mathrm{Ca}^{2+}$ mobilization-inhibitory activity of wood creosote, we evaluated the effect of TTX, a potent nerve axonal blocker, on spontaneous periodic increases in $\left[\mathrm{Ca}^{2+}\right]_{\mathrm{i}}$ in muscle tissue preparations. To investigate whether the enteric nervous system contributes to the generation of spontaneous periodic increases in $\left[\mathrm{Ca}^{2+}\right]_{\mathrm{i}}$, we added TTX to the recording chamber. TTX had little effect on the spontaneous periodic increases in $\left[\mathrm{Ca}^{2+}\right]_{\mathrm{i}}$ (Fig. 5, 6 to $12.5 \mathrm{~min}$ ). Furthermore, in the presence of TTX, wood creosote inhibited the spontaneous periodic increases in $\left[\mathrm{Ca}^{2+}\right]_{\mathrm{i}}$ (Fig. 5, 12.5 to $18 \mathrm{~min}$ ).

To investigate whether the inhibition of $\mathrm{Ca}^{2+}$ mobilization in network regions of ICC is responsible for the $\mathrm{Ca}^{2+}$ mobilization-inhibitory activity of wood creosote, we tested the effects of wood creosote on spontaneous periodic increases in $\left[\mathrm{Ca}^{2+}\right]_{\mathrm{i}}$ in the presence of nifedipine (a dihydropyridine derivative), which selectively blocks voltage-sensitive L-type $\mathrm{Ca}^{2+}$ channels in smooth muscle cells, but not pacemaker activity. ${ }^{23,24)} \mathrm{Ca}^{2+}$ mobilization in smooth muscle cells was excluded under these conditions. Even in the presence of the drug, dihydropyridine-resistant spontaneous periodic increases in $\left[\mathrm{Ca}^{2+}\right]_{\mathrm{i}}$ could be observed (Fig. 6, 8 to $13 \mathrm{~min}$ ). Wood creosote inhibited the dihydropyridine-resistant spontaneous periodic increases in $\left[\mathrm{Ca}^{2+}\right]_{\mathrm{i}}$ (Fig. 6, 15 to $19 \mathrm{~min}$ ). 


\section{DISCUSSION}

In the present study, we demonstrated that wood creosote inhibits the spontaneous periodic increases in $\left[\mathrm{Ca}^{2+}\right]_{\mathrm{i}}$ in guinea pig colonic smooth muscle. The inhibitory effect $\left(\mathrm{IC}_{50}=21 \mu \mathrm{g} / \mathrm{ml}\right)$ in the present study is similar to that $\left(\mathrm{IC}_{50}=17 \mu \mathrm{g} / \mathrm{ml}\right)$ observed in a previous study in which wood creosote suppressed spontaneous phasic contractions of guinea pig ilea ${ }^{16)}$ In addition, the frequency of spontaneous periodic increases in $\left[\mathrm{Ca}^{2+}\right]_{\mathrm{i}}(19 \pm 5$ cycles $/ \mathrm{min})$ was similar to that of spontaneous phasic contractions ( $26 \pm 1$ cycles/min) observed previously. ${ }^{14)}$ Ozaki and colleagues showed that spontaneous periodic increases in $\left[\mathrm{Ca}^{2+}\right]_{\mathrm{i}}$ were superimposed upon spontaneous phasic contractions in the simultaneous measurements of tension and $\left[\mathrm{Ca}^{2+}\right]_{\mathrm{i}}{ }^{25,26)}$ indicating that the spontaneous phasic contractions are accompanied by increases in $\left[\mathrm{Ca}^{2+}\right]_{\mathrm{i}}$. These results suggest that the inhibitory effect of wood creosote on spontaneous periodic increases in $\left[\mathrm{Ca}^{2+}\right]_{\mathrm{i}}$ is at least partially responsible for the suppression of spontaneous phasic contractions of smooth muscle. The six major constituents of wood creosote suppressed the spontaneous phasic contractions of rat and guinea pig ileal muscles. The constituent 4-ethylguaiacol was previously demonstrated to have the most effective suppression of spontaneous phasic contractions. ${ }^{14,15)}$ The present study showed that the six major constituents of wood creosote inhibit spontaneous periodic increases in $\left[\mathrm{Ca}^{2+}\right]_{\mathrm{i}}$ in guinea pig colonic smooth muscle; it is noteworthy that 4-ethylguaiacol was again demonstrated to have the greatest activity in suppressing spontaneous periodic increases in $\left[\mathrm{Ca}^{2+}\right]_{\mathrm{i}}$. These results suggest that the simple phenolic compounds in wood creosote contribute to the inhibition of spontaneous periodic increases in $\left[\mathrm{Ca}^{2+}\right]_{\mathrm{i}}$.

Wood creosote is composed of more than 19 simple phenolic compounds. ${ }^{9)}$ In a differential scanning calorimeter analysis $^{27)}$ of wood creosote, we found that the melting temperature of wood creosote was much lower than that of the individual phenolic compounds due to depression of the freezing point (Kuge, Taiko, unpublished data). This suggests that wood creosote has "mild physical properties" because of the association among the simple phenolic compounds. This observation prompts us to postulate that a mixture of phenolic compounds may also have "milder" pharmacologic properties than individual phenolic compounds. The inhibitory effect of wood creosote $\left(\mathrm{IC}_{50}=21 \mu \mathrm{g} / \mathrm{ml}\right)$ was lower than that of the individual six major constituents of wood creosote $\left(\mathrm{IC}_{50}=1\right.$ to $\left.4 \mu \mathrm{g} / \mathrm{ml}\right)$. In $21 \mu \mathrm{g} / \mathrm{ml}$ of wood creosote, concentrations ( 1 to $6 \mu \mathrm{g} / \mathrm{ml}$ ) of individual major phenolic compounds, which were calculated from percentage $(\mathrm{w} / \mathrm{w})$ of contents, were similar to their $\mathrm{IC}_{50}$ values (1 to $4 \mu \mathrm{g} / \mathrm{ml}$ ). If the individual major phenolic compounds in wood creosote exert complete efficacy, the $\mathrm{IC}_{50}$ value of wood creosote would be within the range of approximately 1 to $4 \mu \mathrm{g} / \mathrm{ml}$. However, the $\mathrm{IC}_{50}$ value of wood creosote was higher than that range. These results may support the hypothesis above. In addition, we have found that wood creosote has lower potential to irritate human skin compared with the individual phenolic compounds, such as phenol, guaiacol, and creosol (data not shown). This implies that the irritation potential of the individual phenolic compounds in wood creosote is attenuated due to their association or interaction. The "mild physi- cal properties" of wood creosote may be useful as a major ingredient of Seirogan ${ }^{\mathrm{TM}}$, which has long been used as a traditional herbal antidiarrheal medicine in Asia.

It is generally considered that activation of GI motility decreases the time during which the epithelium is in contact with the intraluminal fluid, with a resultant decrease in the absorption of the fluid. Therefore the antimotility activity of a medication is thought to contribute at least partially to its antidiarrheal activity. ACh, a synaptic transmitter in intestinal excitatory neurons, ${ }^{28,29}$ has been used as an inducer of intestinal motility in in vitro diarrhea model experiments. In previous reports, wood creosote suppressed ACh-induced tonic contractions of guinea pig ileum in diarrhea model experiments. ${ }^{14-16)}$ The present study showed that wood creosote inhibited $\mathrm{ACh}$-induced $\mathrm{Ca}^{2+}$ responses in guinea pig colonic smooth muscle. These results suggest that the $\mathrm{Ca}^{2+}$ mobilization-inhibitory activity of wood creosote contributes to the suppression of ACh-induced tonic contractions. Thus wood creosote may exert its antidiarrheal effect, at least in part, due to its inhibitory effect on the $\mathrm{Ca}^{2+}$ mobilization in the GI tract.

We postulate that wood creosote exerts its effects on network regions of the ICC. Smooth muscle cells, enteric neurons, and ICC are considered to play key roles in GI motility. Since enteric neurons are involved in controlling GI movements, ${ }^{30,31)}$ we investigated whether the enteric nervous system contributes to the generation of spontaneous periodic increases in $\left[\mathrm{Ca}^{2+}\right]_{i}$. TTX had little effect on the generation of spontaneous periodic increases in $\left[\mathrm{Ca}^{2+}\right]_{\mathrm{i}}$, indicating that they are independent of the enteric nervous system. Furthermore, wood creosote inhibited spontaneous periodic increases in $\left[\mathrm{Ca}^{2+}\right]_{\mathrm{i}}$ in the presence of TTX. These results suggest that wood creosote exerts its effect on smooth muscle cells or network regions of ICC rather than directly on the enteric nervous system. Torihashi and colleagues ${ }^{23)}$ and Nakayama and Torihashi ${ }^{24)}$ reported that $\left[\mathrm{Ca}^{2+}\right]_{\mathrm{i}}$ oscillation in ICC using isolated cell clusters from the mouse small intestine is closely linked to pacemaker activity. Their method can discriminate between the $\mathrm{Ca}^{2+}$ mobilization in ICC and that in smooth muscle cells, using nifedipine $1 \mu \mathrm{M}$ and c-Kit immunoreactivity as a marker of ICC. In the presence of nifedipine $1 \mu \mathrm{M}$, we could observe dihydropyridine-resistant spontaneous periodic increases in $\left[\mathrm{Ca}^{2+}\right]_{\mathrm{i}}$ that were inhibited by wood creosote. These results support the hypothesis that wood creosote exerts its effect on network regions of the ICC. However, in this set of experiments, we could not directly investigate the effect of wood creosote on $\mathrm{Ca}^{2+}$ mobilization in ICC. Additional study is needed to characterize fully the effects of wood creosote on $\mathrm{Ca}^{2+}$ mobilization in the GI tract.

Recently, Huizinga and colleagues have suggested that, as ICCs are unique to the gut, they may be ideal targets for pharmacologic intervention in GI motility disorders, which are common and result in significant health care expenditures by patients and society. ${ }^{32)}$ If ICCs can be controlled, new avenues for therapy may open. Wood creosote may be a suitable candidate for targeting ICC if our hypothesis is correct.

In summary, we demonstrated that wood creosote decreases the amplitude of both spontaneous and ACh-enhanced periodic increases in $\left[\mathrm{Ca}^{2+}\right]_{\mathrm{i}}$ in guinea pig colonic smooth muscle. These results suggest that antimotility activ- 
ity through the inhibition of $\mathrm{Ca}^{2+}$ mobilization in the GI tract is at least partially responsible for the antidiarrheal activity of wood creosote. Wood creosote decreases both TTX- and nifedipine-resistant spontaneous periodic increases in $\left[\mathrm{Ca}^{2+}\right]_{\mathrm{i}}$. Based on these results, we would like to conclude that wood creosote exerts its effect, at least in part, on network regions of ICC.

Acknowledgments We thank Dr. M. Sokabe (Nagoya University Graduate School of Medicine) for technical advice on calcium imaging and Dr. H. Suzuki (Nagoya City University Medical School) for technical advice on muscle preparation.

\section{REFERENCES}

1) Sanders K. M., Gastroenterology, 111, 492-515 (1996)

2) Thomsen L., Robinson T. L., Lee J. C., Farraway L. A., Hughes M. J., Andrews D. W., Huizinga J. D., Nat. Med., 4, 848-851 (1998).

3) Horowitz B., Ward S. M., Sanders K. M., Annu. Rev. Physiol., 61, 19-43 (1999).

4) Maeda H., Yamagata A., Nishikawa S., Yoshinaga K., Kobayashi S., Nishi K., Nishikawa S., Development, 116, 369-375 (1992).

5) Ward S. M., Burns A. J., Torihashi S., Sanders K. M., J. Physiol., 480, 91-97 (1994).

6) Huizinga J. D., Thuneberg L., Kluppel M., Malysz J., Mikkelsen H. B., Bernstein A., Nature (London), 373, 347-349 (1995).

7) Sommerville L. E., Hartshorne D. J., Cell. Calcium, 7, 353-364 (1986).

8) Allen B. G., Walsh M. P., Trends Biochem. Sci., 19, 362-368 (1994).

9) Ogata N., Baba T., Res. Commun. Chem. Pathol. Pharmacol., 66, $411-423$ (1989).

10) Kuge T., Shibata T., Willett M. S., Pharmacotherapy, 23, 1391-1400 (2003).

11) Kuge T., Shibata T., Willett M. S., J. Clin. Pharmacol., 43, 284-290
(2003).

12) Kuge T., Shibata T., Willett M. S., Turck P., Traul K. A., Int. J. Toxicol., 20, 297-305 (2001).

13) Kuge T., Venkova K., Greenwood-Van Meerveld B., Dig. Dis. Sci., 47, 2651-2656 (2002).

14) Ogata N., Toyoda M., Shibata T., Res. Commun. Chem. Pathol. Pharmacol., 77, 359-366 (1992).

15) Toyoda M., Ogata N., Shibata T., Pharmacology, 47, 300-308 (1993).

16) Ogata N., Baba T., Shibata T., Pharmacology, 46, 173-180 (1993).

17) Ataka K., Ogata N., Kuge T., Shibata T., Res. Commun. Mol. Pathol. Pharmacol., 93, 219-224 (1996).

18) Greenwood-Van Meerveld B., Tyler K., Kuge T., Ogata N., Aliment. Pharmacol. Ther., 13, 97-102 (1999).

19) Grynkiewicz G., Poenie M., Tsien R. Y., J. Biol. Chem., 260, 3440 3450 (1985).

20) Yamazawa T., Iino M., J. Physiol., 538, 823-835 (2002).

21) Saito S. Y., Hori M., Ozaki H., Karaki H., J. Smooth Muscle Res., 32, 51-60 (1996).

22) Nakanishi S., Kakita S., Takahashi I., Kawahara K., Tsukuda E., Sano T., Yamada K., Yoshida M., Kase H., Matsuda Y., Hashimoto Y., Nonomura Y., J. Biol. Chem., 267, 2157-2163 (1992).

23) Torihashi S., Fujimoto T., Trost C., Nakayama S., J. Biol. Chem., 277, 19191-19197 (2002).

24) Nakayama S., Torihashi S., Jpn. J. Physiol., 52, 217-227 (2002).

25) Ozaki H., Satoh T., Karaki H., Ishida Y., J. Biol. Chem., 263, 1407414079 (1988).

26) Ozaki H., Stevens R. J., Blondfield D. P., Publicover N. G., Sanders K. M., Am. J. Physiol., 260, C917-C925 (1991).

27) Teramoto Y., Anal. Sci., 6, 635-643 (1990).

28) Eglen R. M., Life Sci., 68, 2573-2578 (2001).

29) Lecci A., Santicioli P., Maggi C. A., Curr. Opin. Pharmacol., 2, 630641 (2002).

30) Hirst G. D., Nature (London), 399, 16-17 (1999).

31) Stevens R. J., Publicover N. G., Smith T. K., Nature (London), 399, 62-66 (1999).

32) Huizinga J. D., Thuneberg L., Vanderwinden J. M., Rumessen J. J., Trends Pharmacol. Sci., 18, 393-403 (1997). 